\title{
Acylcarnitine profiles in serum and muscle of dairy cows receiving conjugated linoleic acids or a control fat supplement during early lactation
}

\author{
Y. Yang, ${ }^{1}$ H. Sadri, ${ }^{2 *}$ † C. Prehn, ${ }^{3}$ J. Adamski, ${ }^{3,4,5}$ J. Rehage,${ }^{6}$ S. Dänicke, ${ }^{7}$ B. Saremi, ${ }^{8}$ and H. Sauerwein ${ }^{1}$ \\ ${ }^{1}$ Institute of Animal Science, Physiology and Hygiene Unit, University of Bonn, 53115 Bonn, Germany \\ ${ }^{2}$ Department of Clinical Science, Faculty of Veterinary Medicine, University of Tabriz, Tabriz 5166616471, Iran \\ ${ }^{3}$ Institute of Experimental Genetics, Genome Analysis Center, Helmholtz Zentrum München, German Research Center for Environmental Health, \\ Neuherberg 85764, Germany \\ ${ }^{4}$ Lehrstuhl für Experimentelle Genetik, Technische Universität München, Freising-Weihenstephan 85350, Germany \\ ${ }^{5}$ German Center for Diabetes Research (DZD), München-Neuherberg 85764, Germany \\ ${ }^{6}$ Clinic for Cattle, University for Veterinary Medicine, Foundation, 30173 Hannover, Germany \\ ${ }^{7}$ Institute of Animal Nutrition, Friedrich-Loeffler-Institute (FLI), 38116 Braunschweig, Germany \\ ${ }^{8}$ Evonik Nutrition \& Care GmbH, Rodenbacher Chaussee 4, 63457 Hanau, Germany
}

\section{ABSTRACT}

Acylcarnitines (ACC) are formed when fatty acid (FA)-coenzyme A enters the mitochondria for $\beta$-oxidation and the tricarboxylic acid cycle through the carnitine shuttle. Concentrations of ACC may vary depending on the metabolic conditions, but can accumulate when rates of $\beta$-oxidation exceed those of tricarboxylic acid. This study aimed to characterize muscle and blood serum acylcarnitine profiles, to determine the mRNA abundance of muscle carnitine acyltransferases, and to test whether dietary supplementation (from d 1 in milk) with conjugated linoleic acids (CLA; $100 \mathrm{~g} / \mathrm{d}$; each $12 \%$ of trans-10,cis-12 and cis-9,trans-11 CLA; $\mathrm{n}=11$ ) altered these compared with control fat-supplemented cows (CTR; $\mathrm{n}=10$ ). Blood samples and biopsies from the semitendinosus musclewere collected on $\mathrm{d}-21,1,21$, and 70 relative to parturition. Serum and muscle ACC profiles were quantified using a targeted metabolomics approach. The CLA supplement did not affect the variables examined. The serum concentration of free carnitine decreased with the onset of lactation. The concentrations of acetylcarnitine, hydroxybutyrylcarnitine, and the sum of short-chain ACC in serum were greater from d -21 to 21 than thereafter. The serum concentrations of long-chain ACC tetradecenoylcarnitine (C14:1) and octadecenoylcarnitine (C18:1) concentrations were greater on $\mathrm{d} 1$ and 21 compared with $\mathrm{d}-21$. Muscle carnitine remained unchanged, whereas short- and medium-chain ACC, including propenoylcarnitine (C3:1), hydroxybutyrylcarnitine, hydroxyhexanoylcarnitine,

Received March 4, 2018.

Accepted August 24, 2018.

*Corresponding author: sadri@tabrizu.ac.ir

$\dagger \mathrm{H}$. Sadri was a visiting scientist at the Institute of Animal Science, Physiology and Hygiene Unit, University of Bonn, Germany, at the time this research was done. hexenoylcarnitine (C6:1), and pimelylcarnitine were increased on d 21 compared with d -21 and decreased thereafter. In muscle, the concentrations of long-chain ACC (from C14 to C18) were elevated on d 1. The mRNA abundance of carnitine palmitoyltransferase 1 , muscle isoform $(C P T 1 B)$ increased 2.8-fold from $\mathrm{d}-21$ to 1 , followed by a decline to nearly prepartum values by d 70, whereas that of CPT2 did not change over time. The majority of serum and muscle short- and long-chain ACC were positively correlated with the FA concentrations in serum, whereas serum carnitine and C5 were negatively correlated with FA. Time-related changes in the serum and muscle ACC profiles were demonstrated that were not affected by the CLA supplement at the dosage used in the present study. The elevated concentrations of long-chain ACC species in muscle and of serum acetylcarnitine around parturition point to incomplete FA oxidation were likely due to insufficient metabolic adaptation in response to the load of FA around parturition.

Key words: acylcarnitine, carnitine shuttle, skeletal muscle, conjugated linoleic acid, early lactation

\section{INTRODUCTION}

The transition from late gestation through early lactation in dairy cows is associated with a substantial mobilization of body reserves, in particular fat, leading to a marked increase in circulating concentrations of fatty acids (FA), which are oxidized by hepatic and extrahepatic tissues as an energy source (Grummer, 1993). However, in the liver, the oxidative capacity for FA and for exporting FA via very low density lipoproteins is limited; thus, fatty liver may result from increased lipolysis (Grummer, 2008). Peroxisomal $\beta$-oxidation, as an auxiliary pathway for oxidizing FA during extensive FA mobilization, helps to dampen accumulation of fat in the liver (Grum et al., 1994, 1996, 2002). In addition, 
the oxidative capacity for FA in other tissues, such as skeletal muscle, may also contribute in reducing the metabolic load of FA on the liver (Kuhla et al., 2011; Schäff et al., 2013), though the quantitative contribution of skeletal muscle to FA metabolism in dairy cows during the periparturient is not known.

In dairy cows, plasma FA mainly comprise SFA, including palmitic acid (C16:0) and stearic acid (C18:0), and oleic acid (C18:1n9c) as a MUFA (Leroy et al., 2005; Tyburczy et al., 2008). For generating energy from long-chain FA, they need to be transported from the cytoplasm into the mitochondrial matrix across the mitochondrial membranes through a carnitine-dependent transport shuttle. This transport system is regulated by carnitine acyltransferases [i.e., carnitine palmitoyltransferase 1 (CPT1; present in the mitochondrial outer membrane) and 2 (CPT2; located on the matrix side of the inner membrane); Flanagan et al., 2010; Schooneman et al., 2014]. Once inside the mitochondria, carnitine and long-chain acyl-CoA are regenerated by CPT2, which can then be further oxidized via the tricarboxylic acid (TCA) cycle and respiratory chain to provide ATP (Schooneman et al., 2013). Deficiencies in these enzymes or impaired functions, or depletion of TCA cycle intermediates, may lead to incomplete mitochondrial FA oxidation, resulting in accumulation of acylcarnitines (ACC), which may be associated with development of insulin resistance, as documented in human studies (Adams et al., 2009; Mihalik et al., 2010; Sun et al., 2016).

Serum ACC undergo time-related changes in dairy cows during the transition from late pregnancy to early lactation (Kenéz et al., 2016) and differ between cows experiencing excessive versus low lipolysis, as classified via the serum FA concentrations postpartum (Humer et al., 2016). The plasma ACC profile may reflect the intramitochondrial acyl-CoA pattern; however, it is not clear to what extent circulating levels of ACC reflect tissue ACC metabolism, as plasma ACC represent the sum from different tissues, mainly skeletal muscle and liver (Schooneman et al., 2014; Xu et al., 2016).

Supplementation with trans-10,cis-12 CLA is used to reduce milk fat content in early-lactation dairy cows as a dietary strategy to improve energy status to counteract the physiological negative energy balance (Sippel et al., 2009; Schlegel et al., 2012). The trans-10,cis-12 isomer is referred as the most effective isomer lowering milk fat content mainly through inhibition of de novo FA synthesis in the mammary gland, accompanied by a reduction of FA uptake from triacylglycerol rich lipoproteins due to inhibition of lipoprotein lipase activity (Bauman et al., 2011). A number of studies have examined the effects of CLA on hepatic lipid metabolism in growing beef cattle (Shibani et al., 2012) or dairy cows
(Schlegel et al., 2012) through assessing expression of genes involved in lipid metabolism; but to our knowledge no evaluation exists of the effects of CLA on lipid metabolism in ruminant skeletal muscle. Considering skeletal muscle to be principal contributor to the serum ACC pool (Koves et al., 2008), we tested the hypothesis that dietary supplementation with CLA may alter the expression of muscle carnitine acyltransferases in conjunct with free carnitine and ACC profiles in both serum and muscle of dairy cows. We compared CLA supplementation with control fat-supplemented cows to address potential changes in capacity for mitochondrial $\beta$-oxidation of FA in skeletal muscle in the context of the negative energy balance typical for early lactation. Using serum samples and biopsies from semitendinosus muscle, we aimed to determine changes in serum and muscle concentrations of ACC and muscle expression of $C P T 1 B$ and CPT2 mRNA related to treatment and time from late pregnancy to lactation.

\section{MATERIALS AND METHODS}

\section{Animals, Treatment, and Experimental Design}

All animal experiments were in accordance with the European Community regulations concerning the protection of experimental animals and the guidelines of the LAVES (Lower Saxony State Office for Consumer Protection and Food Safety, Germany, File Number 33.14.42502-04-071/07). The experimental design and zootechnical data were reported previously (Pappritz et al., 2011a). A subset of animals and samples from that previous study (i.e., only multiparous cows) was considered for the current study. Briefly, 21 Holstein cows, housed in a freestall barn were fed ad libitum with a partial mixed ration according to the recommendations of the German Society of Nutrition Physiology (GfE, 2001). The partial mixed ration (6.8 $\mathrm{MJ}$ of $\mathrm{NE}_{\mathrm{L}} /$ $\mathrm{kg}$ of $\mathrm{DM}$ ) consisted of $37.8 \%$ corn silage, $25.2 \%$ grass silage, and $37 \%$ concentrate (DM basis). At 1 DIM, cows were allotted to either the CLA group $(\mathrm{n}=11)$ or the control group (CTR; $\mathrm{n}=10)$. The animals in the CLA group received $100 \mathrm{~g} / \mathrm{d}$ of encapsulated rumenprotected CLA (Lutrell Pure, BASF SE, Ludwigshafen, Germany) supplying $7.6 \mathrm{~g}$ of cis-9,trans-11 CLA and $7.6 \mathrm{~g}$ of trans-10, cis-12 CLA per day. The animals in the CTR group received $100 \mathrm{~g} / \mathrm{d}$ of rumen-protected control fat supplement (Silafat, BASF), in which CLA was substituted by stearic acid to form an isoenergetic control diet using a fatty acid with the same number of carbon atoms as in CLA. The supplements were provided with $4 \mathrm{~kg}$ of additional concentrate (8.8 MJ of $\mathrm{NE}_{\mathrm{L}} / \mathrm{kg} \mathrm{DM}$ ) from DIM 1 throughout the observation period. 


\section{Blood and Muscle Tissue Sampling}

Blood samples were taken from the jugular vein on $\mathrm{d}-21,1,21$, and 70 relative to parturition using evacuated tubes. Cows were sampled after the morning milking before they had access to the new fresh ration. Blood samples were allowed to clot and centrifuged at $1,500 \times g$ at $4^{\circ} \mathrm{C}$ for $20 \mathrm{~min}$. Serum was recovered and frozen $\left(-80^{\circ} \mathrm{C}\right)$ until analysis. Muscle biopsies (semitendinosus muscle) were collected on $\mathrm{d}-21,1,21$, and 70 relative to parturition, snap-frozen in liquid nitrogen, and stored at $-80^{\circ} \mathrm{C}$ until analysis.

\section{Estimation of Insulin Sensitivity}

Data needed for the estimation of insulin sensitivity were reported elsewhere (Pappritz et al., 2011a). Insulin sensitivity was estimated by calculating the revised quantitative insulin sensitivity check index (RQUICKI) from the data of blood glucose, insulin, and FA (Holtenius and Holtenius, 2007).

\section{Acylcarnitine Profiling}

The acylcarnitine profiles in muscle and serum were determined by flow-injection electrospray ionization MS/MS profiling through targeted metabolomics using the AbsoluteIDQ p180 Kit (BIOCRATES Life Sciences AG, Innsbruck, Austria). Free carnitine and 40 acylcarnitines were simultaneously quantified. The abbreviations, written as Cx:y, are used to describe the total number of carbons and double bonds of all chains, respectively. All analyses were performed in the Helmholtz Zentrum München, German Research Center for Environmental Health, Genome Analysis Center. For serum, $10 \mu \mathrm{L}$ of the thawed sample were applied directly to the assay. For muscle, $25 \mathrm{mg}$ of frozen samples were homogenized and extracted using homogenization tubes with ceramic beads $(1.4 \mathrm{~mm})$ and a Precellys 24 homogenizer with an integrated cooling unit (PEQLAB Biotechnology GmbH, Darmstadt, Germany). We added $3 \mu \mathrm{L}$ of a dry ice cooled mixture of ethanol/phosphate buffer $(85 / 15 \mathrm{vol} / \mathrm{vol})$ to each milligram of frozen muscle tissue. After centrifugation, 10 $\mu \mathrm{L}$ of the homogenate supernatant were applied to the well plate of the p180 kit. The assay procedures of the AbsoluteIDQ p180 Kit, the detailed description of the tissue preparation, and the metabolite nomenclature have been described in detail previously (Zukunft et al., 2013, 2018). Sample handling was performed by a Hamilton Microlab STAR robot (Hamilton Bonaduz AG, Bonaduz, Switzerland) and an Ultravap nitrogen evaporator (Porvair Sciences, Leatherhead, UK) along with standard laboratory equipment. Mass spectromet- ric analyses were done on an API 4000 triple quadrupole system (Sciex Deutschland GmbH, Darmstadt, Germany) equipped with a 1200 Series HPLC (Agilent Technologies Deutschland GmbH, Böblingen, Germany) and a HTC PAL auto sampler (CTC Analytics, Zwingen, Switzerland) controlled by the software Analyst 1.6.1. Data evaluation for quantification of metabolite concentrations and quality assessment was performed with the MetIDQ software package, which is an integral part of the AbsoluteIDQ kit. Internal standards were used as reference for the calculation of metabolite concentrations. The concentrations of the plasma samples were given in micromoles per liter, the concentrations of the tissue samples in picomoles per milligram of tissue, and the concentrations of tissue homogenate in micromoles per liter.

\section{RNA Extraction and Quantitative Real-Time Reverse Transcription-PCR}

The preparation of the samples, including RNA extraction and cDNA synthesis, was described in detail previously (Saremi et al., 2012a,b; Sadri et al., 2015). Quantification of the mRNA of the targeted genes was performed in an Mx3000P cycler (Agilent, Santa Clara, CA) and in accordance with MIQE guidelines (Bustin et al., 2009). Primer sequences and the real-time PCR conditions are shown in Table 1.

The reaction was performed in triplicate in a total volume of $10 \mu \mathrm{L}$ consisting of $2 \mu \mathrm{L}$ of cDNA (diluted 1:4) as template, $1 \mu \mathrm{L}$ of primer mix, $2 \mu \mathrm{L}$ of water, and $5 \mu \mathrm{L}$ of the DyNAmo ColorFlash SYBR Green qPCR Kit master mix (Thermo Scientific, Germany). For each PCR run, a negative-template control for quantitative PCR as well as a negative-template control and noreverse transcriptase control of cDNA were included. A standard curve was generated using serial dilutions of cDNA to calculate efficiency-corrected relative quantities of the targets (run-specific target amplification efficiency). A set of 2 inter-run calibrators was used for each PCR plate to correct for run-to-run variation. The mRNA abundance of the target genes was normalized using the 4 most stable reference genes (Saremi et al., 2012a); namely, emerin (EMD), RNA polymerase II (POLR2A), eukaryotic translation initiation factor 3 $(E I F 3 K)$, and low-density lipoprotein receptor-related protein 10 (LRP10) using qBase ${ }^{\mathrm{PLUS}} 2.0$ (Biogazelle, Ghent, Belgium).

\section{Statistical Analysis}

Statistical analysis of the data was carried out using SAS software (version 9.2; SAS Institute Inc., Cary, $\mathrm{NC})$. The data were tested for normality before analy- 
Table 1. Characteristics of the primers and the real-time PCR conditions

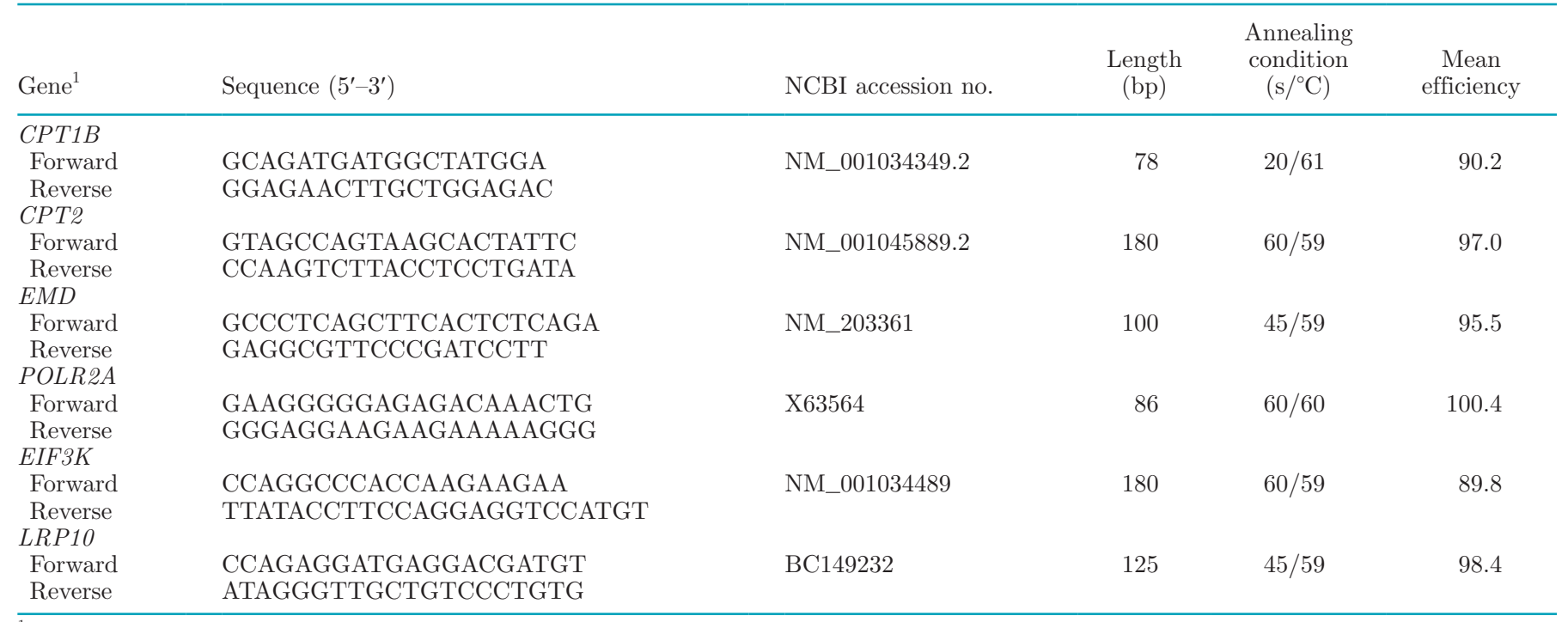

${ }^{1} C P T 1 B=$ carnitine palmitoyltransferase 1, muscle isoform; $C P T 2=$ carnitine palmitoyltransferase $2 ; E M D=$ emerin; $P O L R 2 A=$ RNA polymerase II; EIF3K = eukaryotic translation initiation factor $3 ; L R P 10=$ low-density lipoprotein receptor-related protein 10.

sis using the UNIVARIATE procedure. When the data were not normally distributed (BW, BCS, DMI, and blood glucose, insulin, FA, and RQUICKI), they were transformed using a $\log _{10}$ transformation before analysis. Body weight, BCS, DMI, blood metabolites, and mRNA data were analyzed using repeated measures in the MIXED procedure of SAS. The model included treatment, time, and interaction of treatment $\times$ time as the fixed effects and cow as the random effect. No significant effect of treatment or interaction of treatment $\times$ time were observed on the tested variables. Therefore, data from the 2 feeding groups were merged for the final statistical analysis of the data. The appropriate covariance structure for all repeated statements was determined according to the Akaike information criterion and Bayesian information criterion. The Tukey-Kramer adjustment was applied to account for multiple comparisons. The threshold of significance was set at $P \leq 0.05$; trends were declared at $0.05<P \leq$ 0.10 .

Serum and muscle ACC data were analyzed with MetaboAnalyst 3.0 (Xia et al., 2015). A preliminary statistical analysis of the data showed no significant effect of treatment or interaction of treatment $\times$ time. Thus, data from the 2 feeding groups were merged for the final statistical analysis. The $k$-nearest neighbors algorithm was used to estimate the values of missing data. Metabolites with more than $50 \%$ of missing values (i.e., values lower then limit of detection) were omitted. Data were generalized log-transformed and Pareto-scaled to correct for heteroscedasticity, to reduce the skewness of the data, and to reduce mask effects (van den Berg et al., 2006). Principal component analysis (PCA), partial least squares discriminant analysis (PLS-DA), and variable importance of projection (VIP) were conducted to identify those metabolites showing significant differences among the 4 time points. The PLS-DA models were validated by 10 -fold cross validation and 2,000 permutation tests (Figures 3 and 4; Szymanska et al., 2012). The VIP score was used to rank the metabolites based on their importance in discriminating different time points. In addition, a one-way ANOVA followed by Tukey's HSD test was performed on the data to further confirm the significance of important metabolites identified from PCA and PLS-DA. The threshold of significance was set at false discovery rate (FDR) $\leq 0.10$.

The Spearman rank-order correlation was used to reveal correlations between ACC profiles, mRNA data, and RQUICKI using PROC CORR. The $P$-values were adjusted for multiple comparisons by calculating FDR using PROC MULTTEST. The cutoff condition of correlation analyses was set as $|\rho| \geq 0.20$ and FDR $\leq 0.10$.

\section{RESULTS}

\section{$B W, B C S$, and DMI}

Neither BW nor BCS and DMI were different between groups. As shown in Figure 1 for the merged groups, both BW and BCS decreased with time $(P<0.0001)$, whereas DMI increased with time $(P=0.0002)$. 


\section{RQUICKI}

For RQUICKI, no treatment effects were observed, but RQUICKI tended to decrease by about $4 \%$ from $\mathrm{d}$ 1 to 21 (Figure $2 ; P=0.10$ ).
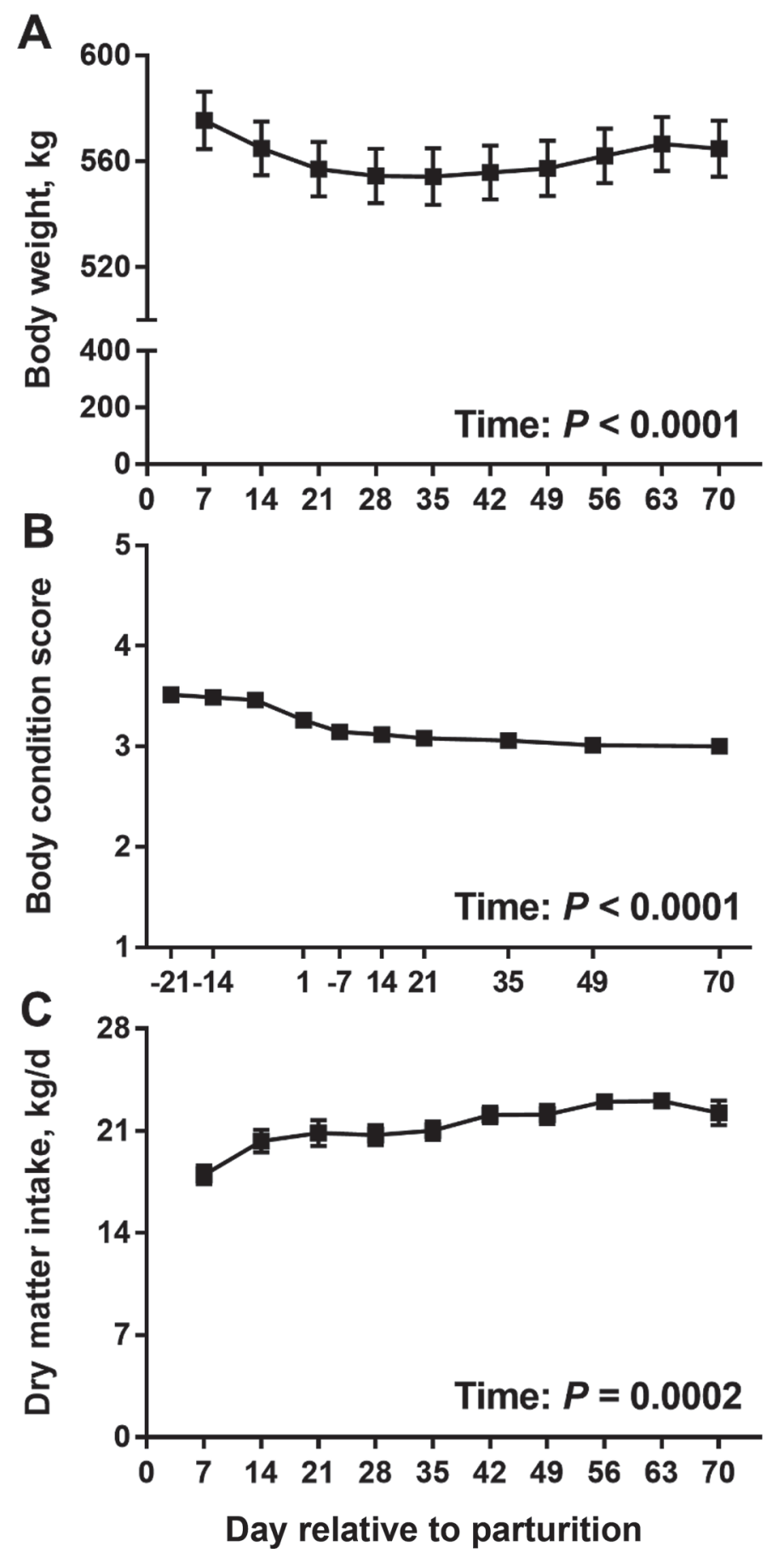

Figure 1. Time course of BW (A), BCS (B), and DMI (C) in dairy cows during late gestation and early lactation. Data are means \pm SEM. Time effect: $P<0.0001$ (BW and BCS) and 0.0002 (DMI).

\section{Acylcarnitine Profiles in Serum}

The serum ACC concentrations were not influenced by CLA supplementation, but changes related to time were observed. With unsupervised and supervised pattern recognition analyses, clear separations between d -21 and postpartum time points in serum were observed (Figures 3A and 3B). Moreover, the top 15 ACC that contributed most significantly to the separation between the 4 time points were identified by the respective validated PLS-DA model and VIP (Figures 3C and 3D). To further confirm the specificity and significance of important metabolites identified from PCA and PLS-DA, we performed univariate analysis using one-way ANOVA and Tukey's HSD test on each metabolite. In total, 7 serum ACC and 3 related indices changed over time (VIP $\geq 1.0$, FDR $<0.10$; Figure 4 ). The serum concentrations of free carnitine decreased with the onset of lactation. The serum concentrations of acetylcarnitine (C2), butyrylcarnitine (C4), and sum of the short-chain ACC concentrations (C2-C5) were elevated around parturition compared with d 70 . The serum concentrations of hydroxybutyrylcarnitine (C4-OH) and octadecenoylcarnitine (C18:1) increased from $\mathrm{d}-21$ to 21 and then remained unchanged. The CPT1 ratio, the ratio of free carnitine to the sum of palmitoylcarnitine and stearoylcarnitine [carnitine/ (C16:1+C18:0)] decreased with the onset of lactation. The CPT2 ratio $[(\mathrm{C} 16: 0+\mathrm{C} 18: 1) / \mathrm{C} 2]$ was higher after parturition compared with prepartum values.

\section{Acylcarnitine Profiles in Skeletal Muscle}

The muscle ACC concentrations did not differ between the groups, but changes related to time were

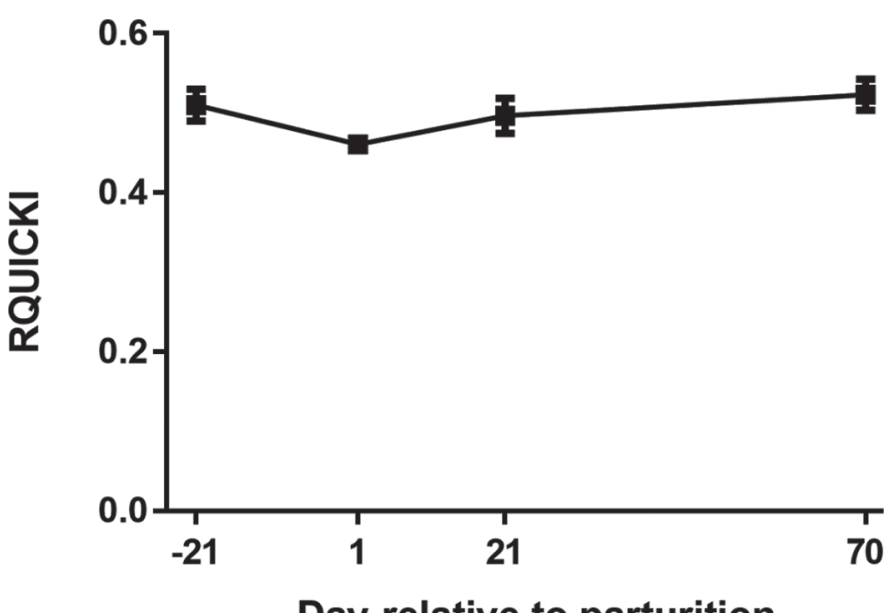

Day relative to parturition

Figure 2. Time course of the estimated insulin sensitivity as measured by the revised quantitative insulin sensitivity check index (RQUICKI) in dairy cows during late gestation and early lactation $(P$ $=0.10$ ). Data are means \pm SEM. 
A

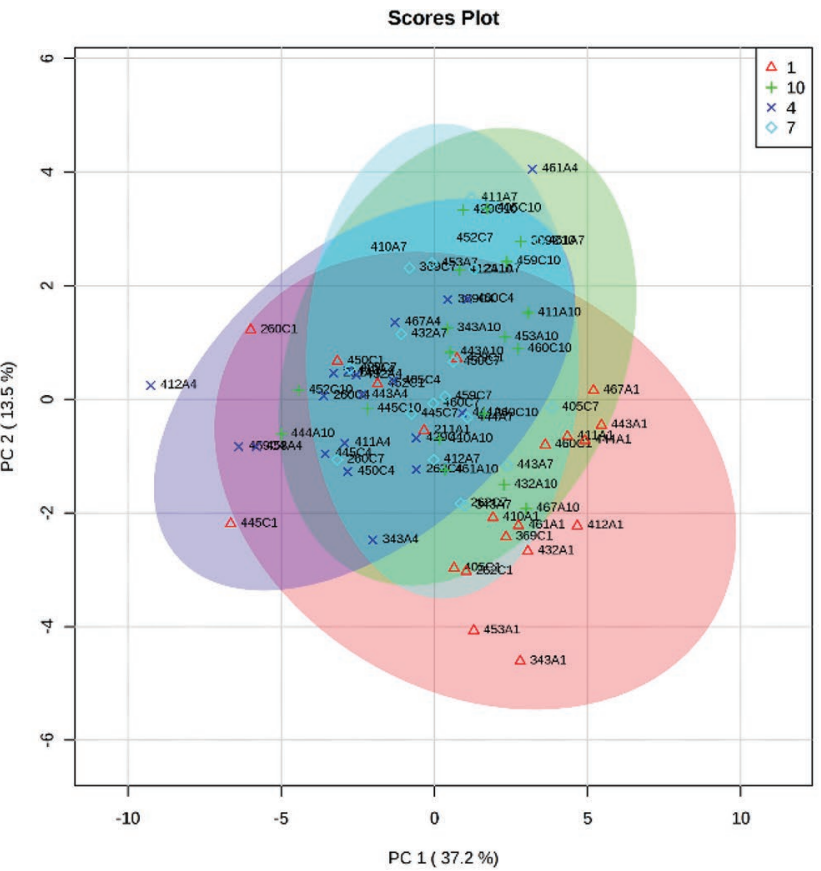

C

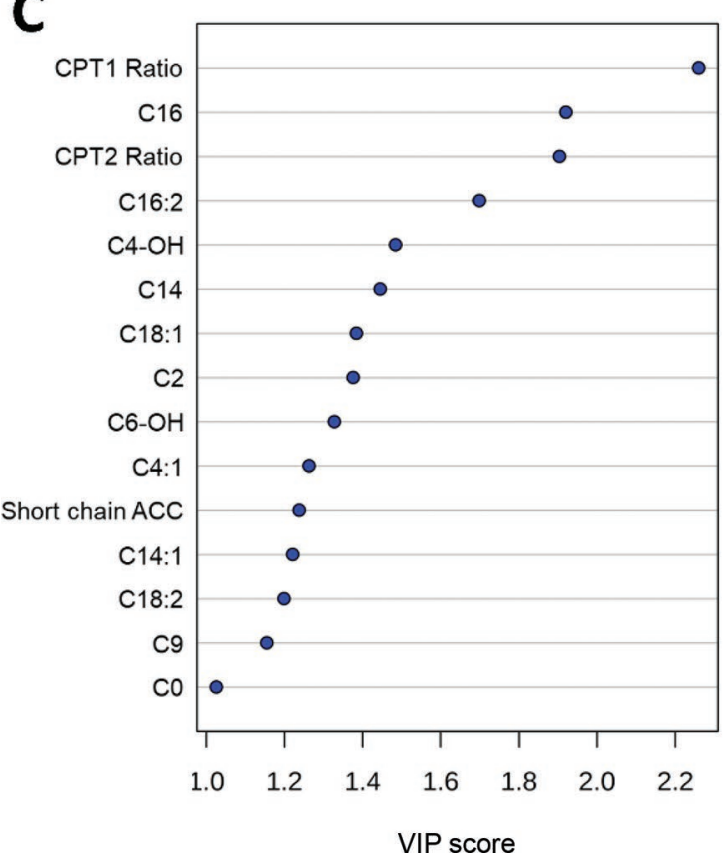

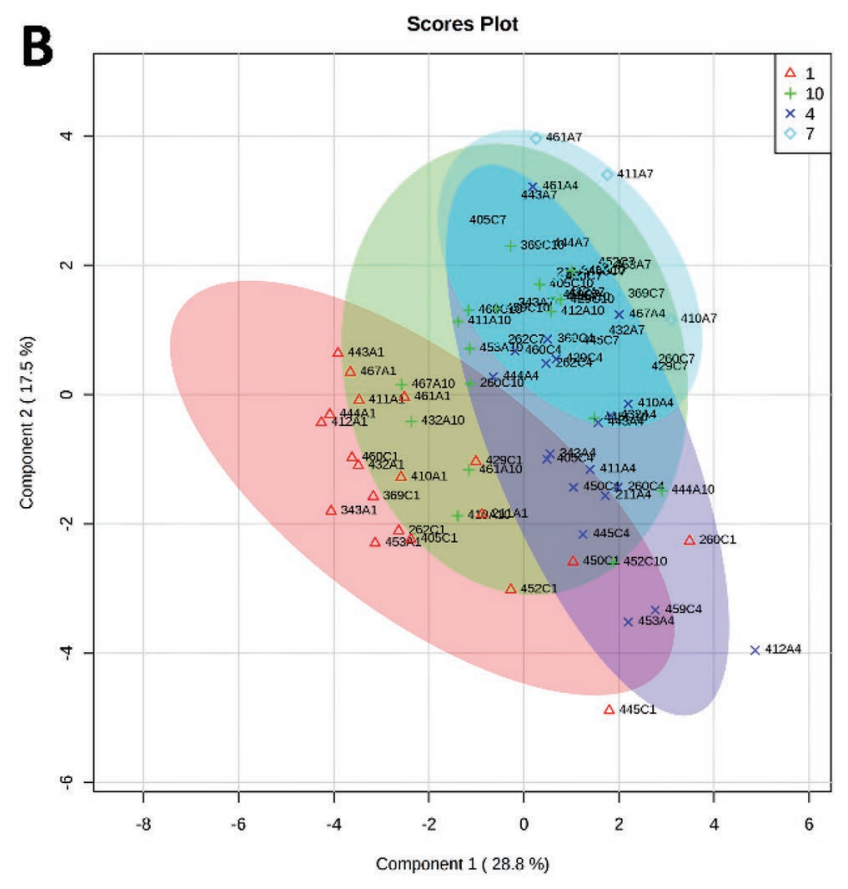

D

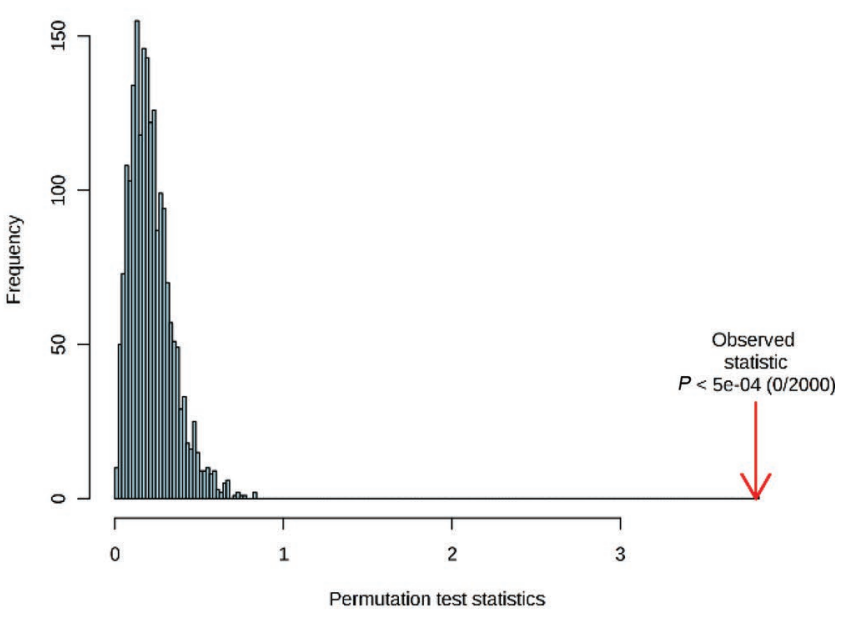

Figure 3. Score plots of principal component analysis (PCA; A) and partial least squares-discriminant (PLS-DA; B) of serum acylcarnitine on $\mathrm{d}-21$ (red), 1 (green), 21 (blue), and 70 (cyan) relative to calving. The top 15 metabolites that contributed most significantly to the separation between the 4 time points were identified according to weights in PLS-DA model by using variable importance in projection (VIP; C). The PLS-DA model was further validated by 2,000 permutation tests based on separation distance (D). The histogram shows the group separation distance formed by these data sets randomly reassigned class labels. The red arrow represents the group separation distance of the original classifier. The further away to the right of the distribution formed by randomly permuted data, the more significant the discrimination. The $P$-value was calculated as the proportion of the times that class separation based on randomly labeled sample is at least as good as the one based on the original data.

observed. Score plots of PCA and PLS-DA of dairy cow muscle ACC are presented in Figure 5A and 5B. The top 15 metabolites that contributed most significantly to the observed separation are shown in Figure 5C.
The top 15 metabolites contributing most significantly (VIP score $>1$ ) to the observed separation are shown in Figure 5C. Time course of the selected metabolites identified to have a VIP score $>1.0$, and FDR $<0.10$ 

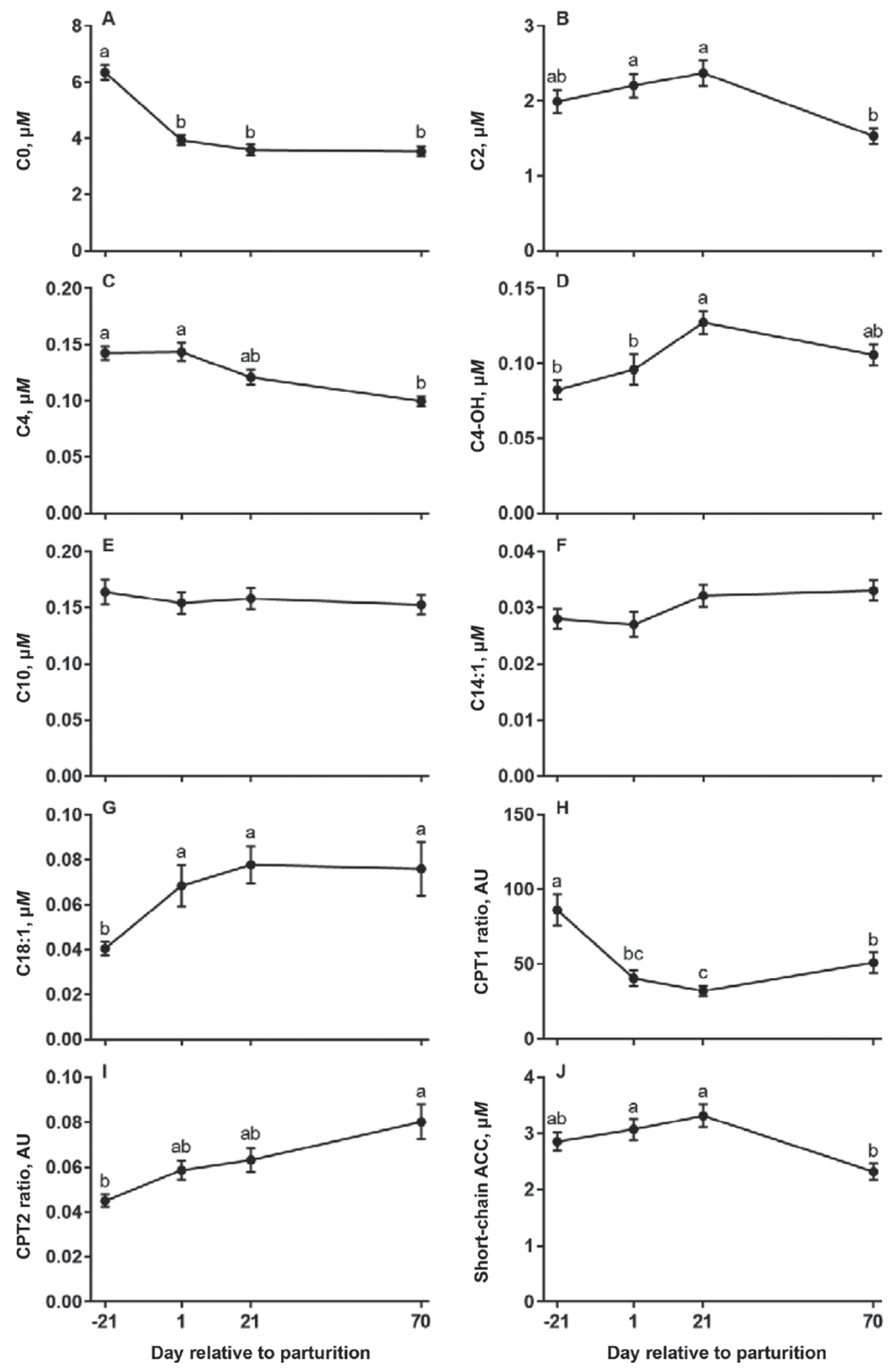

Figure 4. Time course of selected metabolites in serum of dairy cows identified to have a variable importance in projection (VIP) score $>1.0$ and false discovery rate $<0.1$ : free carnitine $(\mathrm{C} 0 ; \mathrm{A})$, acetylcarnitine $(\mathrm{C} 2 ; \mathrm{B})$, butyrylcarnitine $(\mathrm{C} 4$; $\mathrm{C})$, hydroxybutyrylcarnitine $(\mathrm{C} 4-\mathrm{OH}$; D), decanoylcarnitine $(\mathrm{C} 10 ; \mathrm{E})$, tetradecenoylcarnitine $(\mathrm{C} 14: 1 ; \mathrm{F})$, octadecenoylcarnitine $(\mathrm{C} 18: 1 ; \mathrm{G})$, carnitine palmitoyltransferase $(\mathrm{CPT}) 1$ ratio (H), CPT2 ratio (I), and sum of short-chain acylcarnitine (short-chain ACC; C2-C5; J). Data are means \pm SEM. Differences between different time points identified by post-hoc testing (Tukey's HSD) after ANOVA are indicated by different letters (a-c). 
are shown in Figure 6. The muscle concentrations of carnitine remained unchanged (data not shown). Muscle short- and medium-chain ACC, including propenoylcarnitine (C3:1), C4-OH, hydroxyhexanoylcarnitine (C6-OH), and hexenoylcarnitine (C6:1) were elevated from d -21 to 21 and decreased thereafter. Muscle long-chain ACC, including tetradecanoylcarnitine (C14), C14:1, hexadecanoylcarnitine (C16), hydroxyhexadecenoylcarnitine $\quad(\mathrm{C} 16: 1-\mathrm{OH}), \quad \mathrm{C} 18: 1$, hydroxyoctadecenoylcarnitine $(\mathrm{C} 18: 1-\mathrm{OH})$, and sum of the long-chain ACC (C12-C18), changed over time $(P$ $\leq 0.002$ ) and followed a similar pattern; that is, they increased from $\mathrm{d}-21$ to 1 , declined to nearly prepartum values by d 21 , and then remained unchanged. The CPT1 ratio in muscle was decreased from $\mathrm{d}-21$ to a nadir on $\mathrm{d} 1$ and then increased thereafter. In contrast, the muscle CPT2 ratio increased toward parturition and then decreased thereafter.

\section{mRNA Abundance of Carnitine Acyl Transferases in Skeletal Muscle}

No differences were observed between the treatment groups, and thus merged data were analyzed for timedependent effects. The mRNA abundance of $C P T 1 B$ increased 2.8-fold from $\mathrm{d}-21$ to $1(P=0.02)$, followed by a decline to nearly prepartum values by $\mathrm{d} 70$ (Figure 7). The mRNA abundance of CPT2 remained unchanged over time.

\section{Associations of Acylcarnitine Profiles with Conventional Parameters and mRNA Abundance}

As shown in Figure 8, across all time points, correlation analysis revealed a negative correlation between serum FA and CPT1 ratio in muscle and serum $(P$ $<0.0001 ; \rho=-0.46$ and -0.66 , respectively). Positive correlations were observed between serum FA with most of the muscle and serum long-chain ACC (C14-C18; $P<0.03 ; \rho>0.25)$, several muscle shortand medium-chain ACC (C3, C4, C6, C7, C10-derived $\mathrm{ACC}$, and $\mathrm{C} 12: 1 ; P<0.03 ; \rho>0.246)$, serum $\mathrm{C} 2(P$ $<0.0001 ; \rho=0.44)$, and $\mathrm{C} 4-\mathrm{OH}(P<0.01 ; \rho=0.30)$, as well as muscle CPT2 ratio $(P<0.0001 ; \rho=0.46)$. Moreover, FA concentrations were positively related to the $C P T 1 B$ mRNA abundance $(P<0.0001 ; \rho=0.64)$. The RQUICKI were neither associated with the aforementioned ACC nor mRNA abundance.

\section{DISCUSSION}

Skeletal muscle is important for coping with the increasing concentrations of FA at the end of pregnancy and the onset of lactation. The capacity of oxidizing FA likely changes depending on the supply of FA and the physiological status of the animal. We herein characterized the longitudinal changes in ACC both in circulation and in skeletal muscle in dairy cows during the transition from pregnancy into lactation by means of targeted metabolomics and investigated whether dietary supplementation (from 1 DIM) with CLA altered these compared with control-fat supplemented cows. In laboratory animals, CLA supplementation has been associated with metabolic changes favoring the increase of lipolysis and the reduction of lipoprotein lipase activity, accompanied by the oxidation of FA in the adipose and muscle tissues due to increased CPT-1 activity and action or possibly as a result of inhibiting adipocyte differentiation (Botelho et al., 2005; Churruca et al., 2009; Lehnen et al., 2015). In contrast to our hypothesis, treatment with CLA did not affect the variables targeted herein or other classical variables used to characterize the metabolic effects, such as FA. In consequence, the groups could be pooled thus increasing sample size. The reasons for the lack of a CLA response in the examined variables are not known, but are likely related to the dosage used and the availability of the CLA isomers in the intermediary metabolism as well as the timing of the supplementation, which started only with the first day in milk.

The CLA dosages commonly used in dairy cows are far below those tested in laboratory animals and in humans. However, for the main targeted effect in dairy cows (i.e., milk fat reduction), the relatively low dosages are effective. Likewise, the CLA-treated animals in our study had $12 \%$ less milk fat than the control cows; this effect was evident after $28 \mathrm{~d}$ of lactation and CLA supplementation (Pappritz et al., 2011a). However, the transfer of CLA into milk was low and largely limited to the trans-10, cis-12 isoform (0.03 vs. $0.004 \%$ in the control group; Pappritz et al., 2011a). In a more detailed approach using cows fitted with ruminal and duodenal cannulas, the actual duodenal availability of trans-10,cis-12 CLA was determined to be low (i.e., between 5 and 16\%; Pappritz et al., 2011b), though this is in accordance with the protection rate of 9 to $34 \%$ reported for the calcium salts of the CLA (de Veth et al., 2005). Pappritz et al. (2011b) showed that major portions of the CLA reaching the duodenum are excreted via milk $(36-48 \%)$ or feces $(\sim 50 \%)$, and thus only a small proportion of the CLA (i.e., 2-14\%) may reach different tissues and cells. Using the same CLA treatment in primiparous cows that were sequentially slaughtered during lactation, von Soosten et al. (2013) reported only low tissue concentrations. For example, in adipose tissues, a maximum of $0.02 \%$ of total FA were trans-10,cis-12 CLA in supplemented cows; the 
CLA content in control cows remained below the limit of detection $(<0.01 \%$ of total FA). In skeletal muscle tissue, CLA were not detectable (von Soosten et al.,
2013). We thus speculated that a substantially higher dose of CLA would be required to affect FA oxidation in muscle or the studied muscle was less sensitive
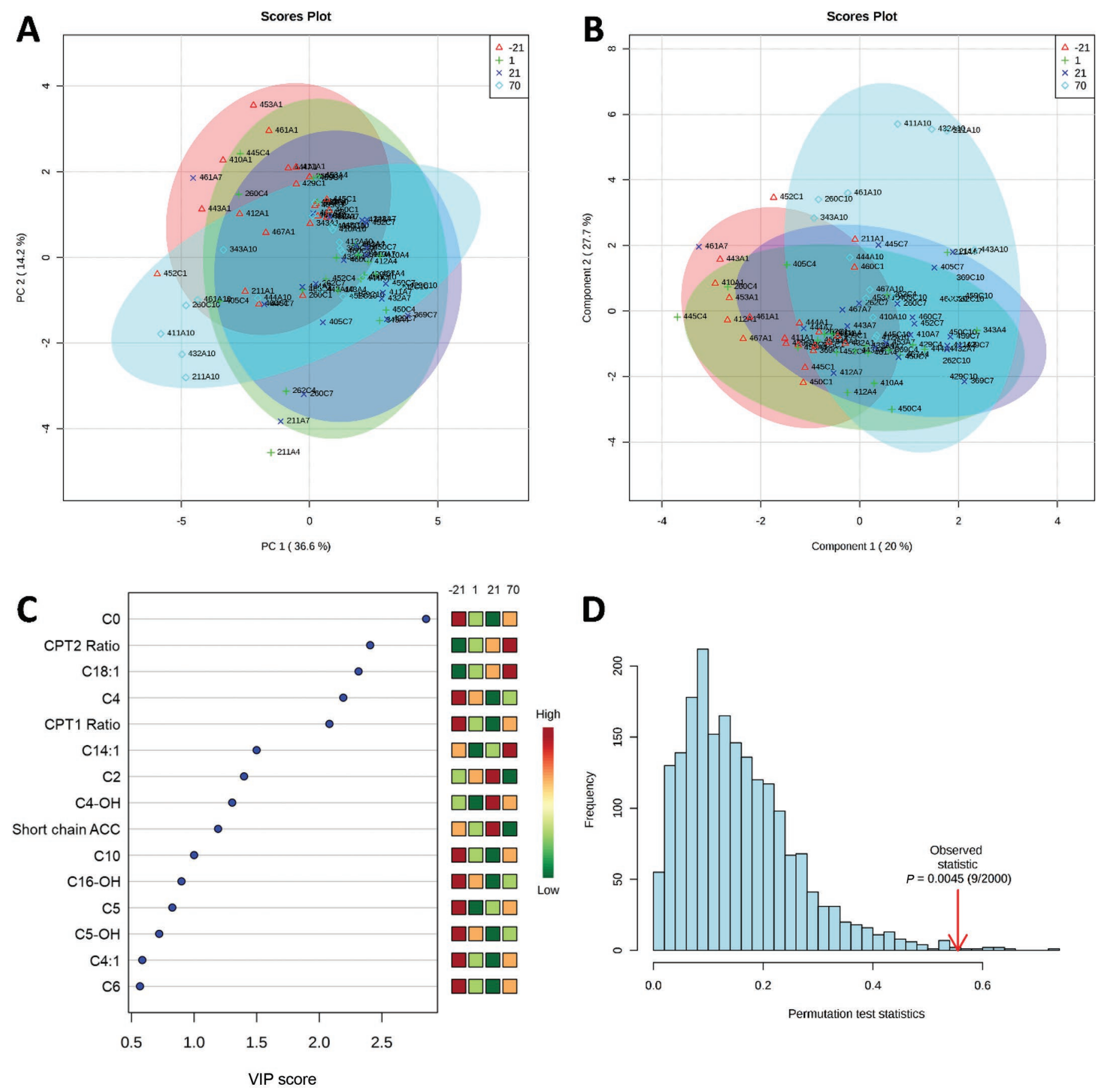

D

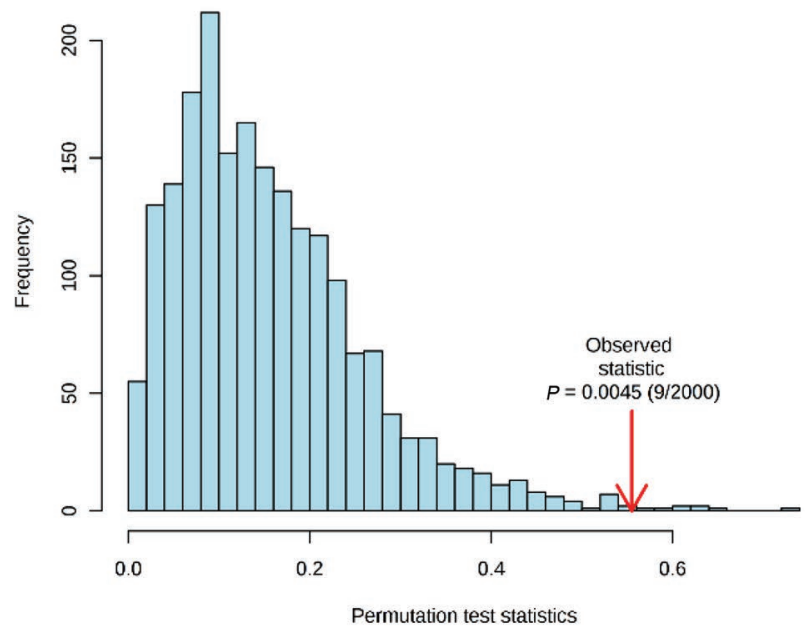

Figure 5. Score plots of principal component analysis (PCA; A) and partial least squares-discriminant (PLS-DA; B) of dairy cow's muscle acylcarnitine on $\mathrm{d}-21$ (red), 1 (green), 21 (blue), and 70 (cyan) relative to calving. Top 15 metabolites that contributed most significantly to the separation between the 4 time points were identified according to weights in PLS-DA model by using variable importance in projection (VIP; C). The PLS-DA model were further validated by 2,000 permutation tests based on separation distance (D). The histogram shows the group separation distance formed by these data sets randomly reassigned class labels. The red arrow represents the group separation distance of the original classifier. The further away to the right of the distribution formed by randomly permuted data, the more significant the discrimination. The $P$-value is calculated as the proportion of the times that class separation based on randomly labeled sample is at least as good as the one based on the original data. 

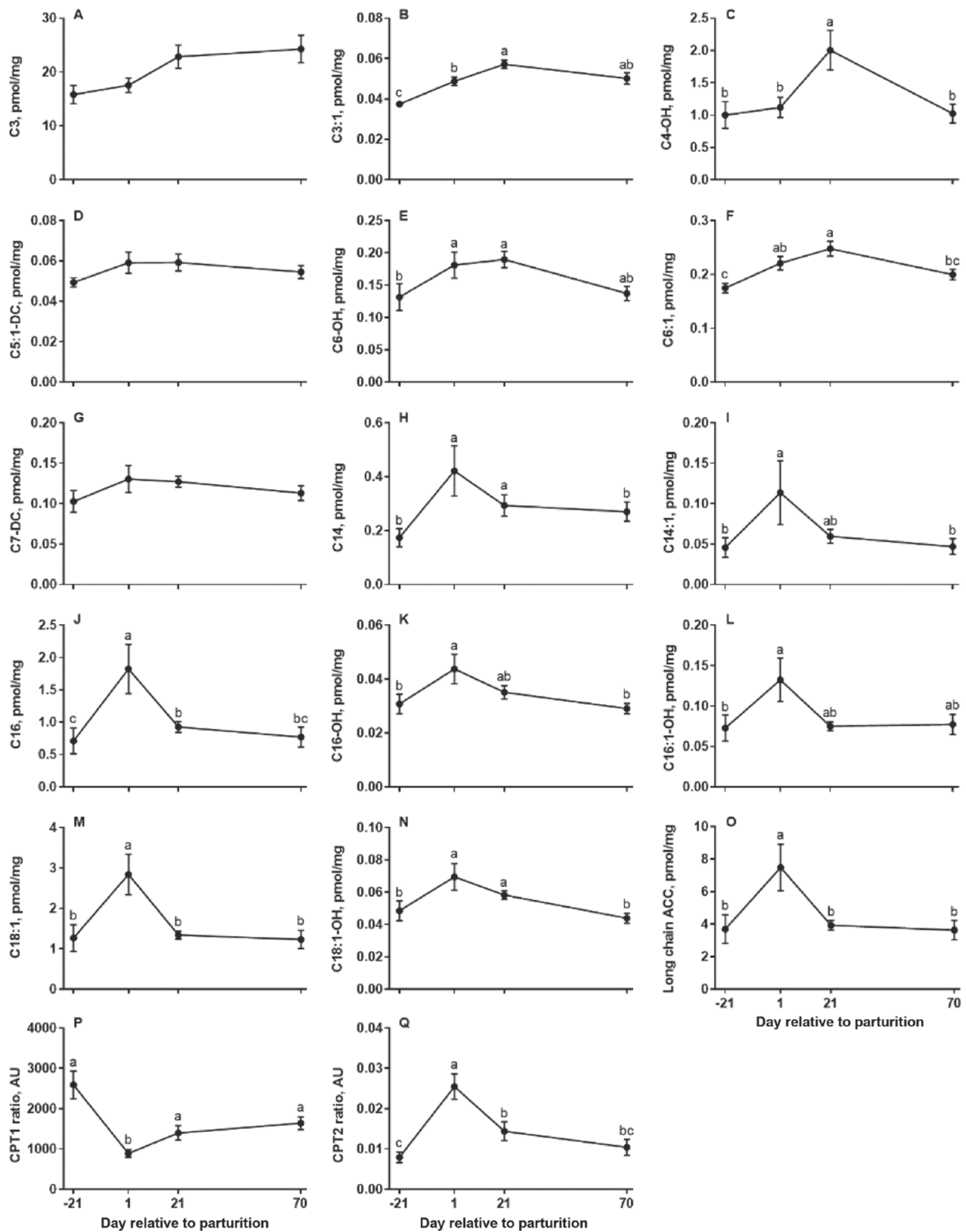

Figure 6. Time course of selected metabolites in muscle of dairy cows identified to have a variable importance in projection (VIP) score $>1.0$ and false discovery rate <0.1: propionylcarnitine $(\mathrm{C} 3$; A), propenoylcarnitine (C3:1; B), hydroxybutyrylcarnitine (C4-OH; C), glutaconylcarnitine (C5:1-DC; D), hydroxyhexanoylcarnitine (C6-OH; E), hexenoylcarnitine (C6:1; F), pimelylcarnitine (C7-DC; G), tetradecanoylcarnitine $(\mathrm{C} 14 ; \mathrm{H})$, tetradecenoylcarnitine $(\mathrm{C} 14: 1$; I), hexadecanoylcarnitine $(\mathrm{C} 16$; J), hydroxyhexadecanoylcarnitine $(\mathrm{C} 16-\mathrm{OH}$; K), hydroxyhexadecenoylcarnitine $(\mathrm{C} 16: 1-\mathrm{OH} ; \mathrm{L})$, octadecenoylcarnitine $(\mathrm{C} 18: 1 ; \mathrm{M})$, hydroxyoctadecenoylcarnitine (C18:1-OH; N), sum of the long-chain acylcarnitine (long-chain ACC, C12+; O), carnitine palmitoyltransferase (CPT) 1 ratio (P), and CPT2 ratio (Q). Data are means \pm SEM. Differences between different time points identified by post-hoc testing (Tukey's HSD) after ANOVA are indicated by different letters $(\mathrm{a}-\mathrm{c})$. 


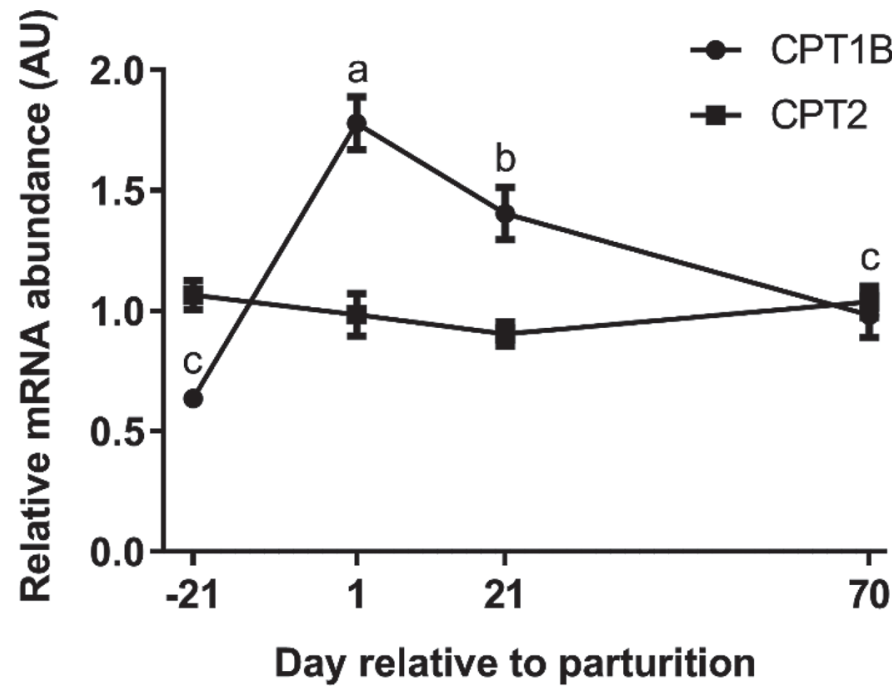

Figure 7. Time course of muscle mRNA abundance (means \pm SEM) of carnitine acyltransferases (CPT1B and CPT2) in dairy cows during late gestation and early lactation. Differences between different time points identified by post-hoc testing (Tukey's HSD) after ANOVA are indicated by different letters $(\mathrm{a}-\mathrm{c})$.

and responsive to CLA. In the current study, muscle samples were biopsied only from the longissimus dorsi muscle, and we also did not determine muscle fiber type composition in the samples. Skeletal muscle, a heterogeneous and highly structured tissue, is composed of a set of fiber types differing in their functional and metabolic profiles (Gunawan et al., 2007), and it is probable that the response of skeletal muscle to the CLA supplement is fiber type dependent, which warrants further investigation.

As expected, we observed greater FA serum concentrations around calving and in the first weeks of lactation, pointing to increased lipolysis around parturition as a response to the massively augmented need for energy to accomplish fetal growth and milk synthesis. Carnitine and its acyl esters (i.e., ACC) are indispensable for the mitochondrial $\beta$-oxidation of FA through facilitating the transfer of long-chain FA from the cytoplasm to the mitochondrial matrix across the mitochondrial membranes. Once inside mitochondria, the enzyme CPT2 reconverts the ACC back into free carnitine and the respective long-chain acyl-CoA, which can then be oxidized for ATP production through $\beta$-oxidation and the TCA cycle (Schooneman et al., 2013). Carnitine is mainly synthesized in the liver from the EAA lysine and methionine (Krajcovicová-Kudlácková et al., 2000). Skeletal muscle, harboring the highest concentrations, is unable to synthesize carnitine and thus needs to take carnitine from blood. In accordance with a previous study (Schooneman et al., 2014), we observed carnitine levels being unchanged in muscle but decreasing in se- rum, likely due to increased carnitine excretion in milk (Shennan et al., 1998) and its uptake by the muscle to maintain the intracellular concentrations. In addition, carnitine maintains the balance between free and esterified $\mathrm{CoA}$ and is required for the mitochondrial efflux of excess acyl groups (Sharma and Black, 2009). Thus, changes in individual serum and tissue ACC may imply changes in specific metabolic pathways; therefore, it is commonly used in neonatal screening for metabolic disturbances (Meyburg et al., 2002). The C2, the shortest ACC, derives from acetyl-CoA via the action of carnitine acetyltransferase for transport out of the mitochondria (Flanagan et al., 2010). Acetylcarnitine is the universal degradation product of all metabolic substrates, and is thus the most abundant ACC in the tissues and circulation. In the current study, serum C2 concentrations were elevated around parturition, pointing to an increased FA $\beta$-oxidation in mitochondria relative to the TCA cycle flux. In addition, $\mathrm{C} 4-\mathrm{OH}$, which can be derived from the CoA ester of the ketone body 3-hydroxybutyrate (Soeters et al., 2012; Schooneman et al., 2013), had higher concentrations around parturition in both serum and muscle. The higher $\mathrm{C} 4-\mathrm{OH}$ concentration, which is thought to reflect ketogenesis (Xu et al., 2016), is also consistent with an excess pool of acetyl-CoA around parturition. Amino acid catabolism is a source of odd-chain species such as C3 and C5 (Flanagan et al., 2010). In the current study, muscle concentrations of C3 and C3:1 were slightly higher after than before calving, whereas those in serum did not show time-dependent changes. These data imply that most lipid-derived ACC increased around parturition, which is consistent with the lactation-induced rise in circulating FA.

We hypothesized that lactation-induced alterations in the ACC profiles are caused by incomplete FA oxidation, as long-chain ACC species were elevated around parturition in both serum and muscle (more notable in the latter). Most long-chain ACC species in muscle decreased from d 1 to 21 , with little or no changes afterward, suggesting insufficient adaptation of their metabolism in response to the metabolic load of FA around parturition. However, it should be noted that, due to the study design, we were unable to assess potential changes during the first days after calving, a period of rapid and substantial metabolic changes in dairy cows. It is likely that FA oxidation should be in relative excess to oxidation in TCA and respiratory chain to guarantee continuous supply of energy. Peroxisomal $\beta$-oxidation, independent of carnitine-mediated transport, is the second pathway through which longchain FA can be oxidized, and unlike mitochondrial $\beta$-oxidation, is not regulated by energy demands of the cell (Osmundsen et al., 1991; Drackley, 1999). For 
A

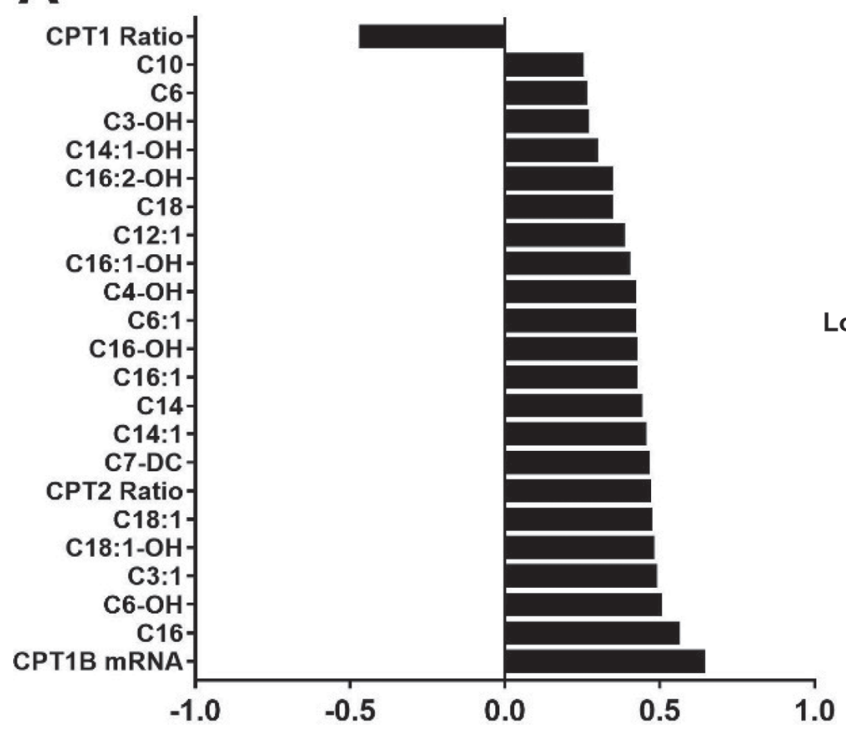

B

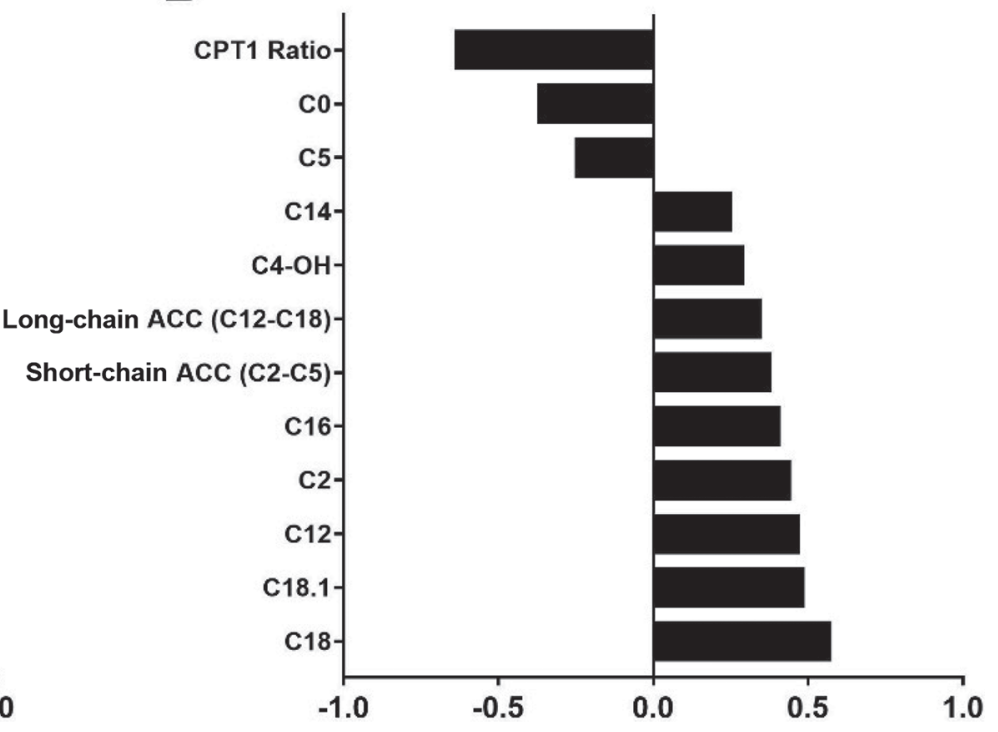

\section{Spearman rank-order correlation coefficient}

Figure 8. Significant Spearman rank-order correlation coefficient $(\rho)$ between serum fatty acid concentration with muscle (A) and serum (B) acylcarnitine (ACC) profiles as well as mRNA abundance. The $P$-values were adjusted for multiple comparisons by calculating the false discovery ratio (FDR). The cutoff condition of correlation analyses was set as $|\rho|>0.20$ and FDR $<0.10$.

bovine liver, the relative contribution of peroxisomal $\beta$-oxidation to total oxidative capacity has been shown to be $>50 \%$, suggesting that this pathway may be a component of the adaptations of FA metabolism in liver during the periparturient period, thus helping the liver cope with the large influx of FA from body fat mobilization (Grum et al., 1994, 1996, 2002). The main function of peroxisomal $\beta$-oxidation is the shortening of the FA chains, preparing them to be completely oxidized in the mitochondria (Drackley, 1999). The role of peroxisomes in metabolism of FA in the skeletal muscle of ruminants has not been determined. It is also probable that peroxisomal oxidation plays a role as an overflow pathway to oxidize FA in muscle of dairy cows during extensive FA mobilization that warrants future investigations.

We also evaluated the CPT1 ratio, as a potential marker for CPT1 deficiency (Fingerhut et al., 2001; CPT1 is a rate-limiting enzyme for long-chain FA entry into the mitochondria for $\beta$-oxidation. An elevation of this ratio has been described in CPT1 deficiency (Fingerhut et al., 2001). In our study, the ratio significantly decreased with the onset of lactation in both serum and muscle, reflecting increased mitochondrial entrance of long-chain FA. Incomplete FA $\beta$-oxidation downstream of CPT1 is associated with elevated levels of plasma ACC (Koves et al., 2008), as acyl-CoA in the mitochondrial matrix can be converted into ACC for transport out of the mitochondria (Koves et al., 2008; Millington and Stevens 2011; Violante et al., 2013). The CPT2 ratio, calculated as the ratio of $\mathrm{C} 16: 0+$ $\mathrm{C} 18: 1$ to $\mathrm{C} 2$, is a potential marker to describe CPT2 deficiency (Gempel et al., 2002). Deficiency of CPT2 is associated with a pronounced elevation of $\mathrm{C} 16: 0$ and C18:1 ACC while C2 is low, pointing to a significant reduction in long-chain FA oxidation. In the present study, the ratio was increased around parturition, likely indicating deficiency or impaired CPT2 functions. In this situation, long-chain ACC cannot be converted to their corresponding acyl-CoA esters, resulting in accumulation of long-chain ACC in the mitochondrial matrix, which are subsequently transported out of the mitochondria to the blood stream (Flanagan et al., 2010; Schooneman et al., 2013). It has been shown that high-fat overfeeding and an increased lipid exposure to skeletal muscle was associated with an increased expression of genes involved in the FA $\beta$-oxidation pathway, including CPT1 that regulates the entry of acyl-CoA into the mitochondrial matrix (Muoio and Newgard, 2006; Noland et al., 2007; Turner et al., 2007). Interestingly, in the current study, the mRNA abundance of CPT1B (muscle isoform) increased 2.8-fold from $\mathrm{d}-21$ to 1 , followed by a decline thereafter, whereas that of CPT2 remained unchanged over time. These data may 
suggest a physiological increase in the capacity of longchain fatty acyl-CoA entry into muscle mitochondria around parturition, but does not seem to coincide with upregulation of downstream metabolic pathways, such as the TCA cycle and respiratory chain. Thus, it is likely that post-CPT1 events, including deficiency or impaired in CPT2 function and depletion of several TCA cycle intermediates, cause an accumulation of ACC in skeletal muscle around parturition.

\section{CONCLUSIONS}

The serum and muscle concentrations of the ACC as well as mRNA expression of the carnitine acyltransferases CPT1B and CPT2 changed with time, but they were not affected by the CLA supplement at the dosage used. Muscle carnitine remained unchanged despite a decline in serum concentrations, likely due to increased carnitine excretion with milk and its uptake by the muscle to maintain intracellular concentrations. The elevated concentrations of muscle long-chain ACC species and serum $\mathrm{C} 2$ around parturition point to increased FA $\beta$-oxidation, which does not seem to coincide with an upregulation of downstream metabolic pathways, such as the TCA cycle and respiratory chain.

\section{ACKNOWLEDGMENTS}

The authors express their appreciation to Inga Hofs and Isabella Israel (Institute of Animal Science, Physiology and Hygiene Unit, University of Bonn, Germany) for their excellent laboratory assistance as well as to Evonik Nutrition \& Care GmbH (Hanau, Germany) for partial financial support of this experiment. Y. Yang is recipient of a scholarship from the China Scholarship Council (CSC, Beijing, China).

\section{REFERENCES}

Adams, S. H., C. L. Hoppel, K. H. Lok, L. Zhao, S. W. Wong, P. E. Minkler, D. H. Hwang, J. W. Newman, and W. T. Garvey. 2009. Plasma acylcarnitine profiles suggest incomplete long-chain fatty acid beta-oxidation and altered tricarboxylic acid cycle activity in type 2 diabetic African-American women. J. Nutr. 139:1073-1081.

Bauman, D. E., K. J. Harvatine, and A. L. Lock. 2011. Nutrigenomics, rumen-derived bioactive fatty acids, and the regulation of synthesis. Annu. Rev. Nutr. 31:299-319.

Botelho, A. P., L. F. Santos-Zago, S. M. P. M. Reis, and A. C. Oliveira. 2005. Conjugated linoleic acid suplementation decreased the body fat in Wistar rats. Br. J. Nutr. 18:561-565.

Bustin, S. A., V. Benes, J. A. Garson, J. Hellemans, J. Huggett, M. Kubista, R. Mueller, T. Nolan, M. W. Pfaffl, G. L. Shipley, J. Vandesompele, and C. T. Wittwer. 2009. The MIQE guidelinesMinimum information for publication of quantitative real-time PCR experiments. Clin. Chem. 55:611-622.

Churruca, I., A. Fernandez-Quintela, and M. P. Portillo. 2009. Conjugated linoleic acid isomers: Differences in metabolism and biological effects. Biofactors 35:105-111. de Veth, M. J., S. K. Gulati, N. D. Luchini, and D. E. Bauman. 2005. Comparison of calcium salts and formaldehyde-protected conjugated linoleic acid in inducing milk fat depression. J. Dairy Sci. $88: 1685-1693$.

Drackley, J. K. 1999. Biology of dairy cows during the transition period: The final frontier? J. Dairy Sci. 82:2259-2273.

Fingerhut, R., W. Roschinger, A. C. Muntau, T. Dame, J. Kreischer, R. Arnecke, A. Superti-Furga, H. Troxler, B. Liebl, B. Olgemoller, and A. A. Roscher. 2001. Hepatic carnitine palmitoyltransferase I deficiency: Acylcarnitine profiles in blood spots are highly specific. Clin. Chem. 47:1763-1768.

Flanagan, J. L., P. A. Simmons, J. Vehige, M. D. Willcox, and Q. Garrett. 2010. Role of carnitine in disease. Nutr. Metab. (Lond.) 7:30.

Gempel, K., S. Kiechl, S. Hofmann, H. Lochmuller, U. Kiechl-Kohlendorfer, J. Willeit, W. Sperl, A. Rettinger, I. Bieger, D. Pongratz, K. D. Gerbitz, and M. F. Bauer. 2002. Screening for carnitine palmitoyltransferase II deficiency by tandem mass spectrometry. J. Inherit. Metab. Dis. 25:17-27.

GfE (German Society of Nutrition Physiology). 2001 Ausschuss für Bedarfsnormen der Gesellschaft für Ernährungsphysiologie. Nr. 8. Empfehlungen zur Energie- und Nährstoffversorgung der Milchkühe und Aufzuchtrinder (Recommendations of Energy and Nutrient Supply for Dairy Cows and Breeding Cattle). DLG-Verlag, Frankfurt am Main, Germany.

Grum, D. E., J. K. Drackley, and J. H. Clark. 2002. Fatty acid metabolism in liver of dairy cows fed supplemental fat and nicotinic acid during an entire lactation. J. Dairy Sci. 85:3026-3034.

Grum, D. E., J. K. Drackley, L. R. Hansen, and J. D. Cremin Jr.. 1996. Production, digestion, and hepatic lipid metabolism of dairy cows fed increased energy from fat or concentrate. J. Dairy Sci. 79:1836-1849.

Grum, D. E., L. R. Hansen, and J. K. Drackley. 1994. Peroxisomal b-oxidation of fatty acids in bovine and rat liver. Comp. Biochem. Physiol. 109B:281-292.

Grummer, R. R. 1993. Etiology of lipid-related metabolic disorders in periparturient dairy cows. J. Dairy Sci. 76:3882-3896.

Grummer, R. R. 2008. Nutritional and management strategies for the prevention of fatty liver in dairy cattle. Vet. J. 176:10-20.

Gunawan, A. M., S. K. Park, J. M. Pleitner, L. Feliciano, A. L. Grant, and D. E. Gerrard. 2007. Contractile protein content reflects myosin heavy-chain isoform gene expression. J. Anim. Sci. 85:12471256.

Holtenius, P., and K. Holtenius. 2007. A model to estimate insulin sensitivity in dairy cows. Acta Vet. Scand. 49:29.

Humer, E., A. Khol-Parisini, B. U. Metzler-Zebeli, L. Gruber, and Q. Zebeli. 2016. Alterations of the lipid metabolome in dairy cows experiencing excessive lipolysis early postpartum. PLoS One 11:e0158633.

Kenéz, Á., S. Dänicke, U. Rolle-Kampczyk, M. von Bergen, and K. Huber. 2016. A metabolomics approach to characterize phenotypes of metabolic transition from late pregnancy to early lactation in dairy cows. Metabolomics 12:165.

Koves, T. R., J. R. Ussher, R. C. Noland, D. Slentz, M. Mosedale, O. Ilkayeva, J. Bain, R. Stevens, J. R. Dyck, C. B. Newgard, G. D. Lopaschuk, and D. M. Muoio. 2008. Mitochondrial overload and incomplete fatty acid oxidation contribute to skeletal muscle insulin resistance. Cell Metab. 7:45-56.

Krajcovicová-Kudlácková, M., R. Simoncic, A. Bederova, K. Babinska, and I. Beder. 2000. Correlation of carnitine levels to methionine and lysine intake. Physiol. Res. 49:399-402.

Kuhla, B., G. Nurnberg, D. Albrecht, S. Görs, H. M. Hammon, and C. C. Metges. 2011. Involvement of skeletal muscle protein, glycogen, and fat metabolism in the adaptation on early lactation of dairy cows. J. Proteome Res. 10:4252-4262.

Lehnen, T. E., M. R. da Silva, A. Camacho, A. Marcadenti, and A. M. Lehnen. 2015. A review on effects of conjugated linoleic fatty acid (CLA) upon body composition and energetic metabolism. J. Int. Soc. Sports Nutr. 12:36.

Leroy, J. L., T. Vanholder, B. Mateusen, A. Christophe, G. Opsomer, A. de Kruif, G. Genicot, and A. Van Soom. 2005. Non-esterified fatty acids in follicular fluid of dairy cows and their effect on 
developmental capacity of bovine oocytes in vitro. Reproduction 130:485-495.

Meyburg, J., A. Schulze, D. Kohlmueller, J. Poschl, O. Linderkamp, G. F. Hoffmann, and E. Mayatepek. 2002. Acylcarnitine profiles of preterm infants over the first four weeks of life. Pediatr. Res. 52:720-723.

Mihalik, S. J., B. H. Goodpaster, D. E. Kelley, D. H. Chace, J. Vockley, F. G. Toledo, and J. P. DeLany. 2010. Increased levels of plasma acylcarnitines in obesity and type 2 diabetes and identification of a marker of glucolipotoxicity. Obesity (Silver Spring) 18:1695-1700.

Millington, D. S., and R. D. Stevens. 2011. Acylcarnitines: Analysis in plasma and whole blood using tandem mass spectrometry. Methods Mol. Biol. 708:55-72.

Muoio, D. M., and C. B. Newgard. 2006. Obesity-related derangements in metabolic regulation. Annu. Rev. Biochem. 75:367-401.

Noland, R. C., T. L. Woodlief, B. R. Whitfield, S. M. Manning, J. R. Evans, R. W. Dudek, R. M. Lust, and R. N. Cortright. 2007. Peroxisomal-mitochondrial oxidation in a rodent model of obesityassociated insulin resistance. Am. J. Physiol. Endocrinol. Metab. 293:E986-E1001.

Osmundsen, H., J. Bremer, and J. I. Pedersen. 1991. Metabolic aspects of peroxisomal b-oxidation. Biochim. Biophys. Acta 1085:141-158.

Pappritz, J., P. Lebzien, U. Meyer, G. Jahreis, R. Kramer, G. Flachowsky, and S. Dänicke. 2011b. Duodenal availability of conjugated linoleic acids after supplementation to dairy cow diets. Eur. J. Lipid Sci. Technol. 113:1443-1455.

Pappritz, J., U. Meyer, R. Kramer, E. M. Weber, G. Jahreis, J. Rehage, G. Flachowsky, and S. Dänicke. 2011a. Effects of long-term supplementation of dairy cow diets with rumen-protected conjugated linoleic acids (CLA) on performance, metabolic parameters and fatty acid profile in milk fat. Arch. Anim. Nutr. 65:89-107.

Sadri, H., S. Dänicke, U. Meyer, J. Rehage, J. Frank, and H. Sauerwein. 2015. Tocopherols and tocotrienols in serum and liver of dairy cows receiving conjugated linoleic acids or a control fat supplement during early lactation. J. Dairy Sci. 98:7034-7043.

Saremi, B., A. Al-Dawood, S. Winand, U. Müller, J. Pappritz, D. von Soosten, J. Rehage, S. Dänicke, S. Häussler, M. Mielenz, and H. Sauerwein. 2012a. Bovine haptoglobin as an adipokine: Serum concentrations and tissue expression in dairy cows receiving a conjugated linoleic acids supplement throughout lactation. Vet. Immunol. Immunopathol. 146:201-211.

Saremi, B., H. Sauerwein, S. Dänicke, and M. Mielenz. 2012b. Technical note: Identification of reference genes for gene expression studies in different bovine tissues focusing on different fat depots. J. Dairy Sci. 95:3131-3138.

Schäff, C., S. Börner, S. Hacke, U. Kautzsch, H. Sauerwein, S. K. Spachmann, M. Schweigel-Röntgen, H. M. Hammon, and B. Kuhla. 2013. Increased muscle fatty acid oxidation in dairy cows with intensive body fat mobilization during early lactation. J. Dairy Sci. 96:6449-6460.

Schlegel, G., R. Ringseis, W. Windisch, F. J. Schwarz, and K. Eder. 2012. Effects of a rumen-protected mixture of conjugated linoleic acids on hepatic expression of genes involved in lipid metabolism in dairy cows. J. Dairy Sci. 95:3905-3918.

Schooneman, M. G., N. Achterkamp, C. A. Argmann, M. R. Soeters, and S. M. Houten. 2014. Plasma acylcarnitines inadequately reflect tissue acylcarnitine metabolism. Biochim. Biophys. Acta 1841:987-994.

Schooneman, M. G., F. M. Vaz, S. M. Houten, and M. R. Soeters. 2013. Acylcarnitines: Reflecting or inflicting insulin resistance? Diabetes 62:1-8.

Sharma, S., and S. M. Black. 2009. Carnitine homeostasis, mitochondrial function, and cardiovascular disease. Drug Discov. Today Dis. Mech. 6:e31-e39.
Shennan, D. B., A. Grant, R. R. Ramsay, C. Burns, and V. A. Zammit. 1998. Characteristics of L-carnitine transport by lactating rat mammary tissue. Biochim. Biophys. Acta 1393:49-56.

Shibani, M., G. Schlegel, E. Most, F. J. Schwarz, R. Ringseis, and K. Eder. 2012. Effect of a rumen-protected conjugated linoleic acid mixture on hepatic lipid metabolism in heifers. J. Anim. Physiol. Anim. Nutr. (Berl.) 96:527-534.

Sippel, M. A., R. S. Spratt, and J. P. Cant. 2009. Milk production responses of primiparous and multiparous dairy cows to dose of conjugated linoleic acid consumed in rumen inert form. Can. J. Anim. Sci. 89:393-399.

Soeters, M. R., M. J. Serlie, H. P. Sauerwein, M. Duran, J. P. Ruiter, W. Kulik, M. T. Ackermans, P. E. Minkler, C. L. Hoppel, R. J. Wanders, and S. M. Houten. 2012. Characterization of D3-hydroxybutyrylcarnitine (ketocarnitine): An identified ketosisinduced metabolite. Metabolism 61:966-973.

Sun, L., L. Liang, X. Gao, H. Zhang, P. Yao, Y. Hu, Y. Ma, F. Wang, Q. Jin, H. Li, R. Li, Y. Liu, F. B. Hu, R. Zeng, X. Lin, and J. Wu. 2016. Early prediction of developing type 2 diabetes by plasma acylcarnitines: A population-based study. Diabetes Care 39:1563-1570

Szymanska, E., E. Saccenti, A. K. Smilde, and J. A. Westerhuis. 2012. Double-check: validation of diagnostic statistics for PLS-DA models in metabolomics studies. Metabolomics 8:3-16.

Turner, N., C. R. Bruce, S. M. Beale, K. L. Hoehn, T. So, M. S. Rolph, and G. J. Cooney. 2007. Excess lipid availability increases mitochondrial fatty acid oxidative capacity in muscle: Evidence against a role for reduced fatty acid oxidation in lipid-induced insulin resistance in rodents. Diabetes 56:2085-2092.

Tyburczy, C., A. L. Lock, D. A. Dwyer, F. Destaillats, Z. Mouloungui, L. Candy, and D. E. Bauman. 2008. Uptake and utilization of trans octadecenoic acids in lactating dairy cows. J. Dairy Sci. 91:3850-3861.

van den Berg, R. A., H. C. J. Hoefsloot, J. A. Westerhuis, A. K. Smilde, and M. J. van der Werf. 2006. Centering, scaling, and transformations: improving the biological information content of metabolomics data. BMC Genomics 7:142.

Violante, S., L. Ijlst, H. Te Brinke, I. Tavares de Almeida, R. J. Wanders, F. V. Ventura, and S. M. Houten. 2013. Carnitine palmitoyltransferase 2 and carnitine/acylcarnitine translocase are involved in the mitochondrial synthesis and export of acylcarnitines. FASEB J. 27:2039-2044.

von Soosten, D., R. Kramer, G. Jahreis, U. Meyer, G. Flachowsky, and S. Dänicke. 2013. Transfer of conjugated linoleic acids into different tissues of dairy cows. Arch. Anim. Nutr. 67:119-133.

Xia, J., I. V. Sinelnikov, B. Han, and D. S. Wishart. 2015. MetaboAnalyst 3.0-making metabolomics more meaningful. Nucleic Acids Res. 43:W251-7.

Xu, G., J. S. Hansen, X. J. Zhao, S. Chen, M. Hoene, X. L. Wang, J. O. Clemmesen, N. H. Secher, H. U. Haring, B. K. Pedersen, R. Lehmann, C. Weigert, and P. Plomgaard. 2016. Liver and muscle contribute differently to the plasma acylcarnitine pool during fasting and exercise in humans. J. Clin. Endocrinol. Metab. 101:5044-5052.

Zukunft, S., C. Prehn, C. Röhring, G. Möller, M. Hrabe de Angelis, J. Adamski, and J. Tokarz. 2018. High-throughput extraction and quantification method for targeted metabolomics in murine tissues. Metabolomics 14:18.

Zukunft, S., M. Sorgenfrei, C. Prehn, G. Möller, and J. Adamski. 2013. Targeted metabolomics of dried blood spot extracts. Chromatographia 76:1295-1305. 